\title{
Musculoskeletal Disorders among Dental Practitioners: Does It Affect Practice?
}

\author{
Dhanya Muralidharan, Nusrath Fareed, and M. Shanthi \\ Department of Public Health Dentistry, Narayana Dental College and Hospital, Chinthareddypalem, Nellore 524002, \\ Andhra Pradesh, India
}

Correspondence should be addressed to Dhanya Muralidharan; kappoordhanya@hotmail.com

Received 22 July 2012; Revised 19 October 2012; Accepted 20 December 2012

Academic Editor: Wolfgang Ahrens

Copyright (c) 2013 Dhanya Muralidharan et al. This is an open access article distributed under the Creative Commons Attribution License, which permits unrestricted use, distribution, and reproduction in any medium, provided the original work is properly cited.

Background. Literature reviews world over have shown a high prevalence of musculoskeletal disorders among dental practitioners. Prevalence of MSD among dental practitioners in India is not well documented. Aim. To determine the prevalence and distribution of MSD among dental practitioners in a city in the southern state of Andhra Pradesh, India. Material and Methods. A cross sectional descriptive study in which a self-administered questionnaire (the Standardized Nordic questionnaire) was used to assess the musculoskeletal symptoms among dental practitioners. The recorded data was analyzed with SPSS 13 . $P$-value $<0.05$ was considered to statistically significant. Results. Seventy-three dental practitioners participated in the study of which seventy-eight percent had a prevalence of at least one MSD symptom over the past twelve months. Most common areas affected by MSD in order of magnitude were neck (52\%), low back (41\%), shoulders (29\%) and wrist (26\%). One third of the practitioners (40\%) required sick leave from their practice during the preceding twelve months. Conclusions. High prevalence of MSD exists among our dental practitioners affecting the daily practice of more than one third. Further studies are needed to identify the specific risk factors for MSD so as to introduce effective remedial measures.

\section{Introduction}

Dentistry is a demanding profession involving high degree of concentration and precision. Dentists require good visual acuity, hearing, depth perception, psychomotor skills, manual dexterity, and ability to maintain occupational postures over long periods [1]. Diminution of any of these abilities affects the practitioner's performance and productivity. Despite numerous advances in dentistry many occupational health problems still persist in modern dentistry [2].

MSD is prevalent world over and is one of the commonest causes of long-term pain and disability affecting hundreds of millions of people. This fact has been recognized by World Health Organization (WHO) and United Nations with their endorsement of the Bone and Joint decade 2000-2010 [3]. MSD is characterized by presence of discomfort, disability or persistent pain in the joints, muscles, tendons, and other soft parts, caused or aggravated by repeated movements and prolonged awkward or forced body postures [4].
Literature reviews across the world have shown a high prevalence of MSD among dentists [5, 6, 7, 8]. Dentists assume static postures at work which require more than $50 \%$ of the body's muscle to contract while resisting gravity [4]. When the body is repeatedly subjected to such prolonged static postures (PSP), it results in pain, injury, or career ending MSD [4]. MSD has an impact not only on the physical but also on the psychological and social aspects of the practitioners $[2,9]$. Work-related MSD in severe cases results in frequent absences and finally to early retirement.

India has been battling traditional public health problems like communicable diseases, malnutrition, growing population, and inadequate medical care, apart from the occupational health problems [9]. MSD is one of the major occupational health problems in India and estimates have shown that MSD contributes to about $40 \%$ of all costs towards the treatment of work related injuries [10]. The prevalence of MSD among dental practitioners is not well documented in India [11]. Hence this study was undertaken 
to determine the prevalence and distribution of MSD among dental practitioners in a city in the southern state of Andhra Pradesh, India.

\section{Material and Methods}

A cross sectional descriptive study was conducted over a period of one month (September, 2010) to assess the prevalence of MSD among dental practitioners in the city. Ethical clearance was obtained from the institutional ethical committee. The purpose of the study was explained to the participants and informed consent was obtained.

A list of the dental practitioners with contact numbers was obtained from the state dental association. Prior appointment was taken through telephone and a self-administered questionnaire was handed over to the dental practitioners at their respective clinics. The method for answering the questionnaire was explained and the questionnaire was collected according to the convenience of the practitioners over a maximum period of one week. A pilot study was performed on five dental practitioners before commencing the study.

The instrument used in this study is the Standardized Nordic Questionnaire (SNQ) [12]. This questionnaire records the prevalence of MSD in terms of musculoskeletal symptoms (ache, pain, discomfort) in the preceding 12 months. SNQ consists of structured, forced, binary, or multiple choice variants. It consists of two parts a general questionnaire and a more specific questionnaire focusing on the neck, shoulders, and low back regions. The general questionnaire records whether musculoskeletal symptoms are present and if so in which area are they localized and whether they are ongoing (presence of musculoskeletal symptoms during the last seven days). The SNQ includes a diagram of the human body viewed from the back, divided into nine anatomical areas. This helps the subjects in identifying the areas of the body to which the questions are directed. These areas have been shown to accumulate musculoskeletal symptoms and are distinguishable from each other by the responder [12]. The recording also included demographic variables such as age, gender, qualification, duration of practice, average patients seen per day, nature of practice, and whether the subjects were right handed or left handed.

The specific questionnaire focuses on anatomical areas in which the musculoskeletal symptoms are most common (neck, shoulders and low back regions) [12]. These questions analyze more thoroughly the severity of the symptoms in terms of their effect on activities at work, during leisure time, and in terms of total duration of symptoms and sick leave during the preceding 12 months.

\section{Statistical Analysis}

Statistical package for social sciences (SPSS) version 13 was used to determine frequency distributions, means and proportions. Comparison of proportions was done using Fischer's exact test. $P$-value of less than 0.05 was considered to be statistically significant.

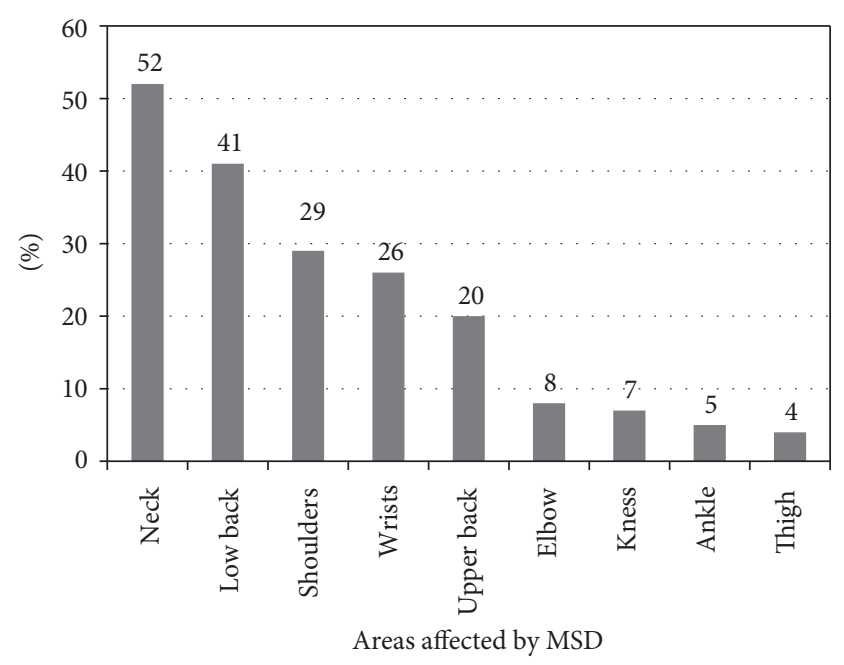

FIGURE 1: Prevalence of MSD in relation to the area involved.

\section{Results}

Out of the 80 dental practitioners registered with the state dental council, 76 were available during the period of the study. Three practitioners refused to participate due to their busy practice schedule which accounted for a response proportion of $96 \%$. The demographic details are presented in Table 1. Majority of the practitioners are males (68\%) and less than 45 years of age (90\%). General dental practitioners accounted to $56 \%$ of the studied subjects and remaining were specialists (Table 1). Majority of the specialists were Prosthodontists (28\%). The average duration of practice was $9.7 \pm 9.4$ years. Most of the practitioners were attending to less than 40 patients per day.

\section{Prevalence of MSD}

Overall $78 \%$ of the practitioners had a prevalence of at least one MSD symptom over the past twelve months. The most common areas affected with MSD in order of magnitude were the neck (52\%), low back (41\%), shoulders (29\%), and wrists (26\%) (Figure 1). Prevalence of MSD was similar for male and female practitioners irrespective of the area involved (Table 2). All practitioners above 45 years of age had MSD (Table 1), however this was not statistically significant when compared to practitioners below 45 years of age. No particular trend was observed between occurrence of MSD and the number of years of practice (Table 1).

MSD prevalence was highest among the orthodontists (100\%) and oral physicians (100\%) (Figure 2). Irrespective of the qualification and specialization the most commonly involved area was the neck. Prevalence of MSD was not significantly different between full time and part time practitioners $(P=0.33)$. All practitioners attending to more than 40 patients per day reported $100 \%$ prevalence of MSD (Table 1). Three fourth of the practitioners reported a 12 month prevalence of musculoskeletal symptoms in more than one area of the body and $25 \%$ had symptoms in more than three areas (Table 3 ). 
TABLE 1: Sociodemographics of the subjects studied in relation to the prevalence of MSD.

\begin{tabular}{|c|c|c|c|c|}
\hline Sociodemographic variables & $\begin{array}{l}\text { Practitioners }(\%) \\
\qquad(N=73)\end{array}$ & $\begin{array}{c}\text { Prevalence of }{ }^{*} \text { MSD (\%) } \\
(N=73)\end{array}$ & $95 \% \mathrm{CI}$ & $P$ value \\
\hline Sex & & & & 0.36 \\
\hline Males & 68 & 74 & $60-84$ & \\
\hline Females & 32 & 87 & $67-96$ & \\
\hline Age group (years) & & & & 0.33 \\
\hline$\leq 45$ years & 90 & 76 & $64-84$ & \\
\hline$>45$ years & 10 & 100 & $59-100$ & \\
\hline Qualification & & & & 0.15 \\
\hline General practitioners & 56 & 85 & $71-93$ & \\
\hline Specialists & 44 & 69 & $51-82$ & \\
\hline Nature of practice & & & & 0.33 \\
\hline Full time & 74 & 81 & $68-89$ & \\
\hline Part time & 26 & 68 & $45-84$ & \\
\hline Number of patients seen per day & & & & 0.76 \\
\hline$\leq 20$ & 77 & 77 & $64-86$ & \\
\hline $21-40$ & 18 & 77 & $49-92$ & \\
\hline$>40$ & 5 & 100 & $49-100$ & \\
\hline Duration of practice in years & & & & 0.32 \\
\hline$\leq 10$ years & 75 & 75 & $61-84$ & \\
\hline$>10$ years & 25 & 89 & $65-98$ & \\
\hline
\end{tabular}

TABLE 2: Area wise predilection of MSD in relation to sex of the dental practitioners.

\begin{tabular}{lccc}
\hline Area affected & $\begin{array}{c}\text { Males }(\%) \\
95 \% \text { CI }\end{array}$ & $\begin{array}{c}\text { Females (\%) } \\
95 \% \text { CI }\end{array}$ & $P$ value \\
\hline Neck & 50 & 57 & 0.625 \\
Shoulders & $(36-63)$ & $(36-74)$ & \\
& 28 & 30 & 1.000 \\
Low back & $(17-41)$ & $(15-51)$ & \\
Wrist & 38 & 48 & 0.453 \\
& $(25-51)$ & $(29-67)$ & \\
Upper back & 26 & 26 & 1.000 \\
Elbow & $(15-39)$ & $(12-46)$ & \\
& 20 & 22 & 1.000 \\
Knee & $(11-33)$ & $(9-42)$ & \\
& $(5-24)$ & 0 & 0.168 \\
Ankle & 8 & 4 & 1.000 \\
Thigh & $(2-19)$ & $(0-22)$ & \\
\hline * & 6 & 4 & 1.000 \\
\hline
\end{tabular}

${ }^{*} 12$ month prevalence of MSD.

\section{Effect of MSD on the Practitioners}

In majority of the practitioners musculoskeletal symptoms lasted for 1-7 days irrespective of the site as shown in Figure 3. MSD was seen to be an ongoing problem in $27 \%$ of the dental practitioners on assessment of the seven day
TABLE 3: Distribution of the dental practitioners in relation to the number of areas involved by MSD.

\begin{tabular}{lcc}
\hline No. of Areas Involved by MSD* & Number & Proportion (\%) \\
\hline One area & 20 & 35 \\
Two areas & 14 & 25 \\
Three areas & 9 & 16 \\
Four areas & 10 & 18 \\
Five areas & 3 & 5 \\
Nine areas & 1 & 2 \\
${ }^{*} 12$ month prevalence of MSD. & &
\end{tabular}

TABLE 4: Effect of MSD on the daily activities of the studied subjects.

\begin{tabular}{lccc}
\hline & $\begin{array}{c}\text { Low back } \\
\text { MSD (\%) }\end{array}$ & $\begin{array}{c}\text { Neck MSD } \\
(\%)\end{array}$ & $\begin{array}{c}\text { Shoulder } \\
\text { MSD (\%) }\end{array}$ \\
\hline Reduction in work activity & 40 & 44 & 30 \\
Reduction in leisure activity & 20 & 37 & 16 \\
Alteration of duties & 40 & 37 & - \\
Doctor consultations & 47 & 41 & 47 \\
Hospitalizations & 3 & - & - \\
Sick leaves & & & \\
$\quad$ 1-7 days & 30 & 29 & 29 \\
\multicolumn{1}{l}{ 8-30 days } & 10 & 5 & 9 \\
\hline
\end{tabular}

${ }^{*} 12$ month prevalence of MSD.

prevalence. The effect of MSD (neck, shoulders, and low back regions) on the daily activities of the practitioners is presented in Table 4. MSD had resulted in doctor consultations, 


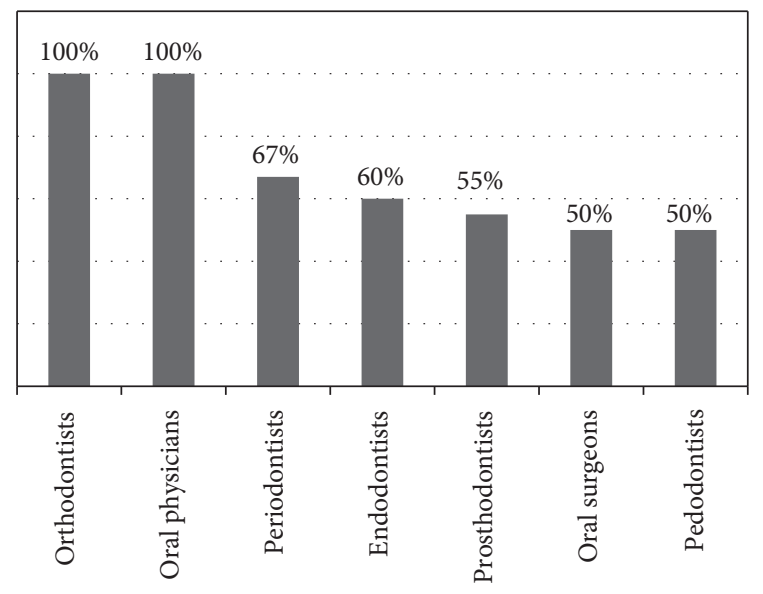

FIgURE 2: Prevalence of MSD in relation to specialization of dental practitioners.

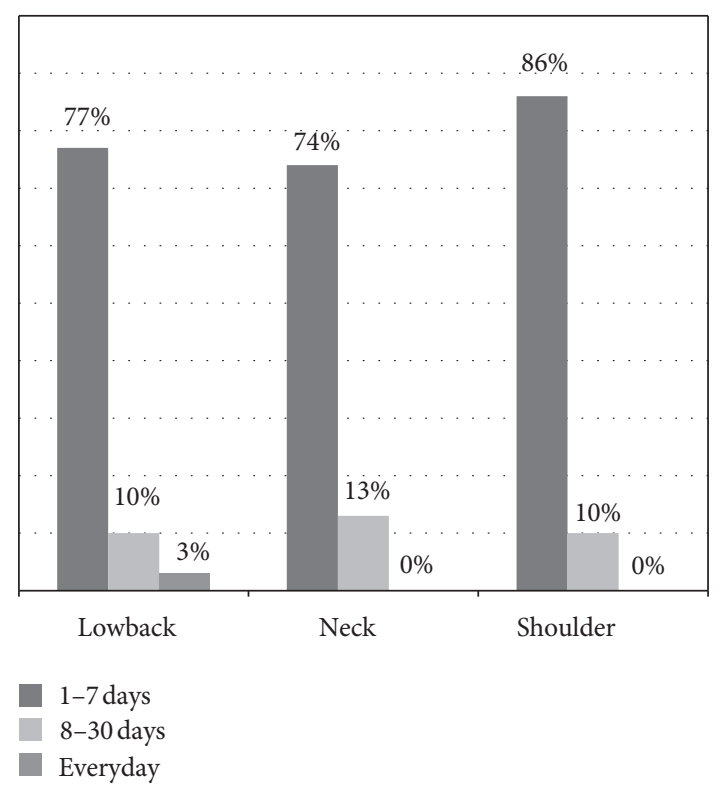

FIGURE 3: Duration of MSD per episode of occurrence.

sick leaves, hospitalizations, alteration of duties as well as reduction in work activity and leisure activity (Table 4 ). More than one third of the practitioners $(40 \%)$ required sick leave (1-7 days) from their practice during the preceding twelve months.

\section{Discussion}

Published literature has shown a high prevalence of MSD among dentists $[5,6,7,8]$. This has been attributed to prolonged static postures, repetitive movements, use of force and vibrations, which are considered to be risk factors for MSD $[4,8,13]$. In severe cases MSD results in frequent absences from work and finally to early retirement $[2,9]$. In India the prevalence of MSD among dental practitioners is not well documented. Hence this study was undertaken to determine the prevalence and distribution of MSD among dental practitioners in a city in the southern state of Andhra Pradesh.

Musculoskeletal disorders are a diverse group of disorders with regard to pathophysiology. According to World Health Organization (WHO), the burden of MSD can be assessed in terms of problems associated with them, that is the pain and impaired functioning (disability) related to the musculoskeletal system or in relation to the cause such as joint disease or trauma [3]. The instrument used in this study is the SNQ which records musculoskeletal symptoms and screens for musculoskeletal disorders in an ergonomic context [12]. SNQ is shown to be valuable in occupational health care service research as screening for musculoskeletal symptoms serves as a diagnostic tool for analyzing the work environment and identifying incompatibilities in the working environment [12].

The present study has revealed a moderately high prevalence $(78 \%)$ of MSD among dental practitioners in the city. This prevalence though higher than that reported by practitioners in Saudi Arabia (59.2\%) [14] was lower than reports from Australia (87.2\%) [15], Lithuania (86.5\%) [13], and Turkey (94\%) [16]. Compared to other health care professionals, the prevalence of MSD in the past 12 months among our sample was higher than reports among medical physicians (41.7\%) in Iran [17] but lower than that of physiotherapists in Nigeria (91.3\%) [18]. The prevalence of MSD among dental practitioners in the present study was much higher than the general Indian population $(25.9 \%$, $N=2086$ ) as evident from a recent community based cross sectional study by Bihari et al. in the national capital of India [19].

Studies assessing the prevalence of MSD among dental practitioners in Lithuania [20] and New Zealand [1] have shown higher prevalence of MSD among female practitioners. This was attributed to the fact that women were more concerned about their health compared to men and tended to report health problems more often. Prevalence of MSD among the general population of India showed females to have higher prevalence compared to the males [19]. The current study in contrast revealed no difference in prevalence of MSD between male and female practitioners. This could be due to the small sample size $(N=73)$ and the fact the majority of the practitioners in our study are males hence female practitioners could have been under represented.

Dentists are predisposed to pain or injury in different regions of the body depending on the type of work and the position adopted [4]. In the present study the commonly affected areas were neck (52.1\%), low back (41.1\%), and shoulders (28.8\%). This pattern of distribution was similar to studies from Queensland [7] and New Zealand [1]. These results indicate that most of the practitioners adopt positions which frequently result in MSD of the neck and low back regions. However Szymańska [21] and Pureine et al. [22] in their series have reported MSD of low back to be the most prevalent musculoskeletal complaint.

Assessment of MSD in different regions of the body have shown that in male practitioners MSD of the elbow region is more common whereas in females the common regions 
affected were shoulders, neck, wrist/hand, and upper back regions $[1,9]$. The present study revealed no such differences which could be attributed to the small sample size.

Studies among dental practitioners in Lithuania and Poland $[13,22]$ have shown MSD to increase with age. The results of the present study similarly showed that all practitioners in the oldest age group had MSD however this prevalence was not significantly different from practitioners below 45 years of age. Our study sample comprised of only 73 dental practitioners which could be the reason for lack of statistical significance. In contrast other studies among dental practitioners of Saudi Arabia and New South Wales showed MSD decreases with age and duration of practice $[14,23]$. Their findings were attributed to older practitioners taking up less number of patients as a result of age or with the years of practice having developed coping measures (adjusting position, better ergonomically oriented dental chairs, exercise, medication and rest) for MSD.

Dental hygienists and periodontists are shown to be predisposed to neck, shoulder, and wrist pain largely due to the static postures combined with forceful, repetitive movements adopted while performing procedures [4]. General practitioners tend to be predisposed to neck and low back MSD due to their prolonged static postures (PSP) and fewer repetitive motions while working [4]. Other studies have shown that Orthodontists have predominantly low back pain because of the repeated forward positioning of head and bending of low back during clinical procedures [24]. The present study revealed highest prevalence of MSD among orthodontists, oral physicians, and general practitioners and irrespective of qualification and specialty the most prevalent site affected was the neck. This lack of difference in predilection of MSD could be attributed to the fact that in India specialists also do general practices apart from their area of specialization.

MSD affects the physical, psychological, and social aspects of practitioners $[9,15]$. This in turn impacts on their productivity and ultimately reducing the quality of life of the practitioners. In the present study, over a period of 12 months, MSD has affected the practitioners as evident from the reduction in work activity, leisure activity, percentage taking sick leaves, consultations with doctor and hospitalization. More than one third (40\%) of the practitioner's required sick leaves which is higher than those reported by the Australian dental practitioners (10\%) [25] but lower than the Polish study by Szymańska [21]. Majority of the practitioners took 1-7 days of sick leaves from practice irrespective of the site of MSD which was in accordance with other studies $[1,26]$.

MSD was seen to be an ongoing problem in about one third of the (27\%) of the dental practitioners as evident from the seven day prevalence results. The severe form of MSD involving more than three anatomical areas was seen in $25 \%$ of the practitioners and this is similar to the findings of Solidaki et al. among three Greek occupational groups (nurses, office workers, and postal clerks) [27].

Literature has shown that predisposing factors for MSD are multifactorial $[8,28,29]$ and may be attributed to posture, repetitious movements, physical loads, psychological stress, and other ergonomic factors. Due to the cross sectional design of the study the causal variables could not be identified which can be considered as a limitation of the present study. The subjectivity of the responses may also be considered as a limitation. Practitioners with recent episodes of MSD will remember the events much better and hence can affect the response to the questionnaire. The major limitation of this study however is the sample size $(N=73)$ which limits the generalizability of the findings. Larger sample size would have improved the power of the study.

The high prevalence of MSD in this study suggests the need to identify the factors predisposing to MSD among the dental practitioners. This might be due to lack of an ergonomically oriented work practice among the Indian dental practitioners; however further studies need to be conducted in order to make logical conclusions. India has a population of 1.21 billion people [30] and 1,04,603 registered practicing dentists [31] providing oral health care for the people. The dentist population ratio of India is $1: 12,437.46$ [31] when compared to the WHO recommendation of $1: 7500$ [32]. Against this background of large population, rising oral health care needs, and inadequate dental manpower, the health and efficiency of the dental care practitioner play a key role in the providing optimal oral health care.

To conclude, a high prevalence of MSD exists among the dental practitioners which affects the daily practice of more than one third of them. Further studies are needed to identify the specific risk factors for MSD so as to introduce effective remedial measures.

\section{References}

[1] K. M. S. Ayers, W. M. Thomson, J. T. Newton, K. C. Morgaine, and A. M. Rich, "Self-reported occupational health of general dental practitioners," Occupational Medicine, vol. 59, no. 3, pp. 142-148, 2009.

[2] P. A. Leggat, U. Kedjarune, and D. R. Smith, "Occupational health problems in modern dentistry: a review," Industrial Health, vol. 45, no. 5, pp. 611-621, 2007.

[3] A. D. Woolf and B. Pfleger, "Burden of major musculoskeletal conditions," Bulletin of the World Health Organization, vol. 81, no. 9, pp. 646-656, 2003.

[4] B. Valachi and K. Valachi, "Preventing musculoskeletal disorders in clinical dentistry: strategies to address the mechanisms leading to musculoskeletal disorders," Journal of the American Dental Association, vol. 134, no. 12, pp. 1604-1612, 2003.

[5] T. U. Lehto, H. Y. Helenius, and H. T. Alaranta, "Musculoskeletal symptoms of dentists assessed by a multidisciplinary approach," Community Dentistry and Oral Epidemiology, vol. 19, no. 1, pp. 38-44, 1991.

[6] P. Lindfors, U. Von Thiele, and U. Lundberg, "Work characteristics and upper extremity disorders in female dental health workers," Journal of Occupational Health, vol. 48, no. 3, pp. 192-197, 2006.

[7] M. J. Hayes, D. R. Smith, and D. Cockrell, "Prevalence and correlates of musculoskeletal disorders among Australian dental hygiene students,' International Journal of Dental Hygiene, vol. 7, no. 3, pp. 176-181, 2009.

[8] T. Morse, H. Bruneau, and J. Dussetschleger, "Musculoskeletal disorders of the neck and shoulder in the dental professions," Work, vol. 35, no. 4, pp. 419-429, 2010. 
[9] E. C. Alexopoulos, I. C. Stathi, and F. Charizani, "Prevalence of musculoskeletal disorders in dentists," BMC Musculoskeletal Disorders, vol. 5, article 16, 2004.

[10] H. N. Saiyed and R. R. Tiwari, "Occupational health research in India," Industrial Health, vol. 42, no. 2, pp. 141-148, 2004.

[11] Y. Mamatha, V. Gopikrishna, and D. Kandaswamy, "Carpal tunnel syndrome: survey of an occupational hazard," Indian Journal of Dental Research, vol. 16, no. 3, pp. 109-113, 2005.

[12] I. Kuorinka, B. Jonsson, A. Kilbom et al., "Standardised Nordic questionnaires for the analysis of musculoskeletal symptoms," Applied Ergonomics, vol. 18, no. 3, pp. 233-237, 1987.

[13] A. Puriene, V. Janulyte, M. Musteikyte, and R. Bendinskaite, "General health of dentists. Literature review," Stomatologija, vol. 9, no. 1, pp. 10-20, 2007.

[14] T. A. Abduljabbar, "Musculoskeletal disorders among dentists in Saudi Arabia," Pakistan Oral and Dental Journal, vol. 28, no. 1, pp. 135-144, 2000.

[15] P. A. Leggat and D. R. Smith, "Musculoskeletal disorders self-reported by dentists in Queensland, Australia," Australian Dental Journal, vol. 51, no. 4, pp. 324-327, 2006.

[16] Z. Polat, S. Başkan, S. Altun, and I. Tacir, "Musculoskeletal symptoms of dentists from South-East Turkey," Biotechnology and Biotechnological Equipment, vol. 21, no. 1, pp. 86-90, 2007.

[17] R. Mehrdad, J. T. Dennerlein, and M. Morshedizadeh, "Musculoskeletal disorders and Ergonomic hazards among Iranian physicians," Archives of Iranian Medicine, vol. 15, no. 6, pp. 370-374, 2012.

[18] B. O. A. Adegoke, A. K. Akodu, and A. L. Oyeyemi, "Workrelated musculoskeletal disorders among Nigerian Physiotherapists," BMC Musculoskeletal Disorders, vol. 9, article 112, 2008.

[19] V. Bihari, C. Keshavachandran, B. S. Pangtey, A. K. Srivastava, and N. Mathur, "Musculoskeletal pain and its associated risk factors in residents of National capital region," Indian Journal of Occupational and Environmental Medicine, vol. 15, no. 2, pp. 59-63, 2011.

[20] A. Puriene, I. Balciuniene, V. Janulyte, and J. Tutkuveien, "Specificity of chronic self reported occupational hazards among male and female Lithuanian dentists," Acta Medica Lituanica, vol. 15, pp. 55-60, 2008.

[21] J. Szymańska, "Disorders of the musculoskeletal system among dentists from the aspect of ergonomics and prophylaxis," Annals of Agriculture and Environmental Medicine, vol. 9, no. 2, pp. 169-173, 2002.

[22] A. Puriene, J. Aleksejuniene, J. Petrauskiene, I. Balciuniene, and V. Janulyte, "Self-reported occupational health issues among Lithuanian dentists," Industrial Health, vol. 46, no. 4, pp. 369-374, 2008.

[23] E. D. Marshall, L. M. Duncombe, R. Q. Robinson, and S. L. Kilbreath, "Musculoskeletal symptoms in New South Wales dentists," Australian Dental Journal, vol. 42, no. 4, pp. 240-245, 1997.

[24] T. M. Newell and S. Kumar, "Prevalence of musculoskeletal disorders among orthodontists in Alberta," International Journal of Industrial Ergonomics, vol. 33, no. 2, pp. 99-107, 2004.

[25] P. A. Leggat and D. R. Smith, "Musculoskeletal disorders self-reported by dentists in Queensland, Australia," Australian Dental Journal, vol. 51, no. 4, pp. 324-327, 2006.

[26] N. Pargali and N. Jowkar, "Prevalence of musculoskeletal pain among dentists in Shiraz, Southern Iran," International Archives of Occupational and Environmental Health, vol. 1, no. 2, pp. 60-74, 2010.
[27] E. Solidaki, L. Chatzi, P. Bitsios et al., "Work-related and psychological determinants of multisite musculoskeletal pain," Scandinavian Journal of Work, Environment and Health, vol. 36, no. 1, pp. 54-61, 2010.

[28] P. M. Bongers, C. R. De Winter, M. A. J. Kompier, and V. H. Hildebrandt, "Psychosocial factors at work and musculoskeletal disease," Scandinavian Journal of Work, Environment and Health, vol. 19, no. 5, pp. 297-312, 1993.

[29] N. Warren, "Causes of musculoskeletal disorders in dental hygienists and dental hygiene students: a study of combined biomechanical and psychosocial risk factors," Work, vol. 35, no. 4, pp. 441-454, 2010.

[30] 2012, http://www.censusindia.gov.in/Census_Data_2001/National_Summary/National_Summary_DataPage.aspx.

[31] http://cbhidghs.nic.in/writereaddata/mainlinkFile/Human\% 20Resources\%20in\%20Health\%20Sector\%202010.pdf.

[32] N. Sandesh and A. Mohapatra, "Street dentistry: time to tackle quackery," Indian Journal of Dental Research, vol. 20, no. 1, pp. $1-2,2009$. 


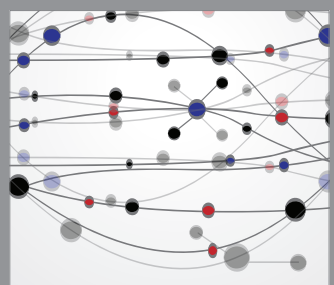

The Scientific World Journal
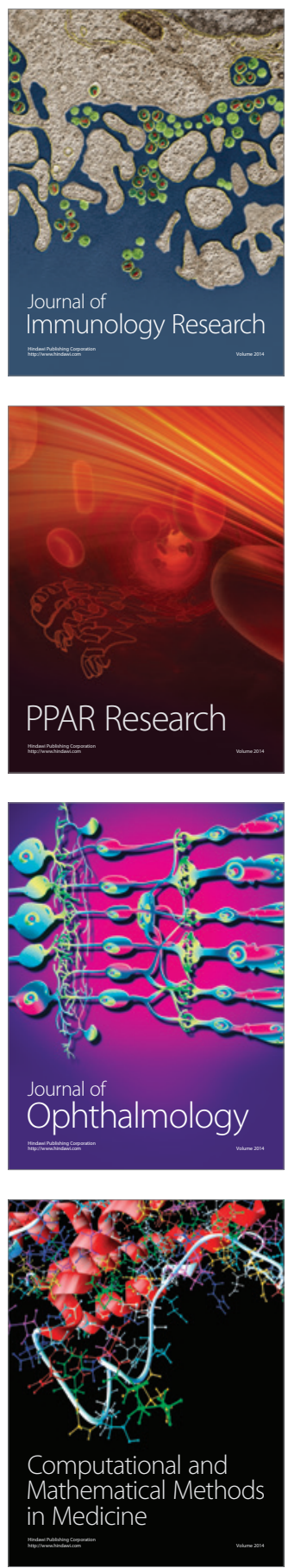

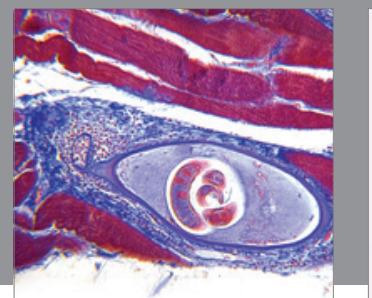

Gastroenterology

Research and Practice
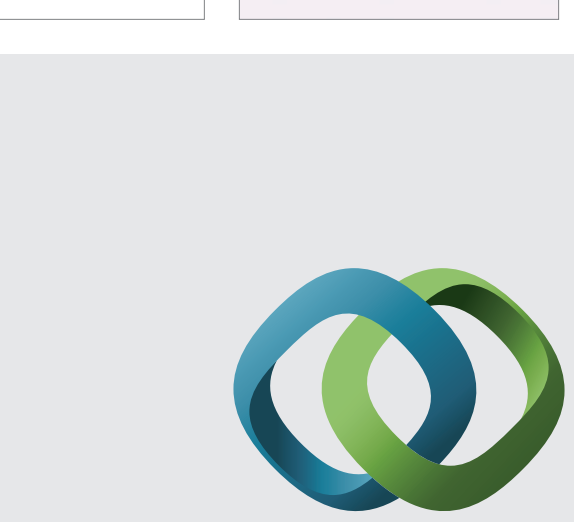

\section{Hindawi}

Submit your manuscripts at

http://www.hindawi.com
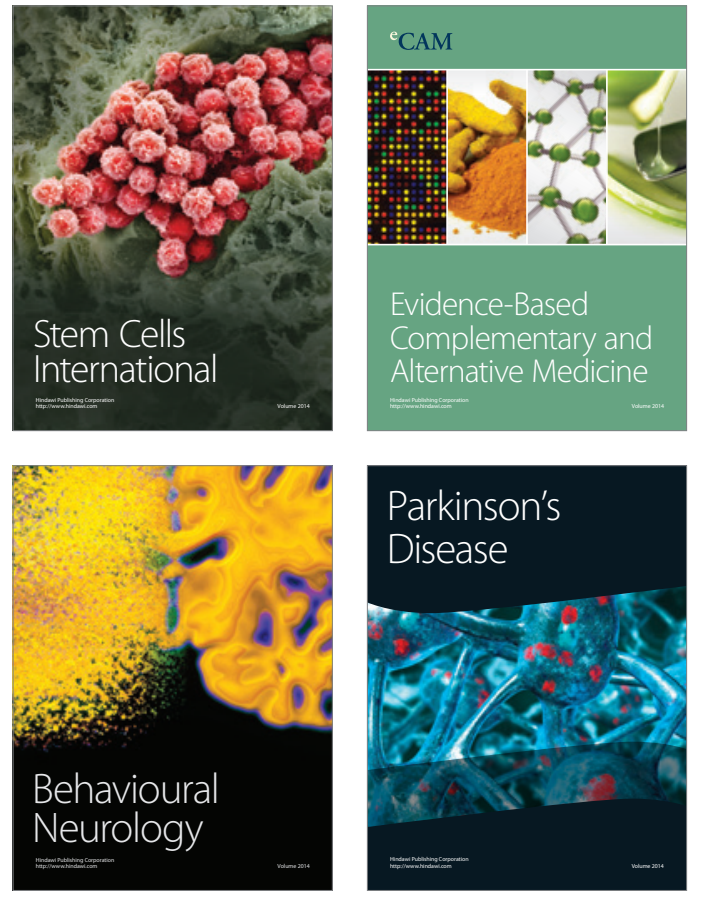
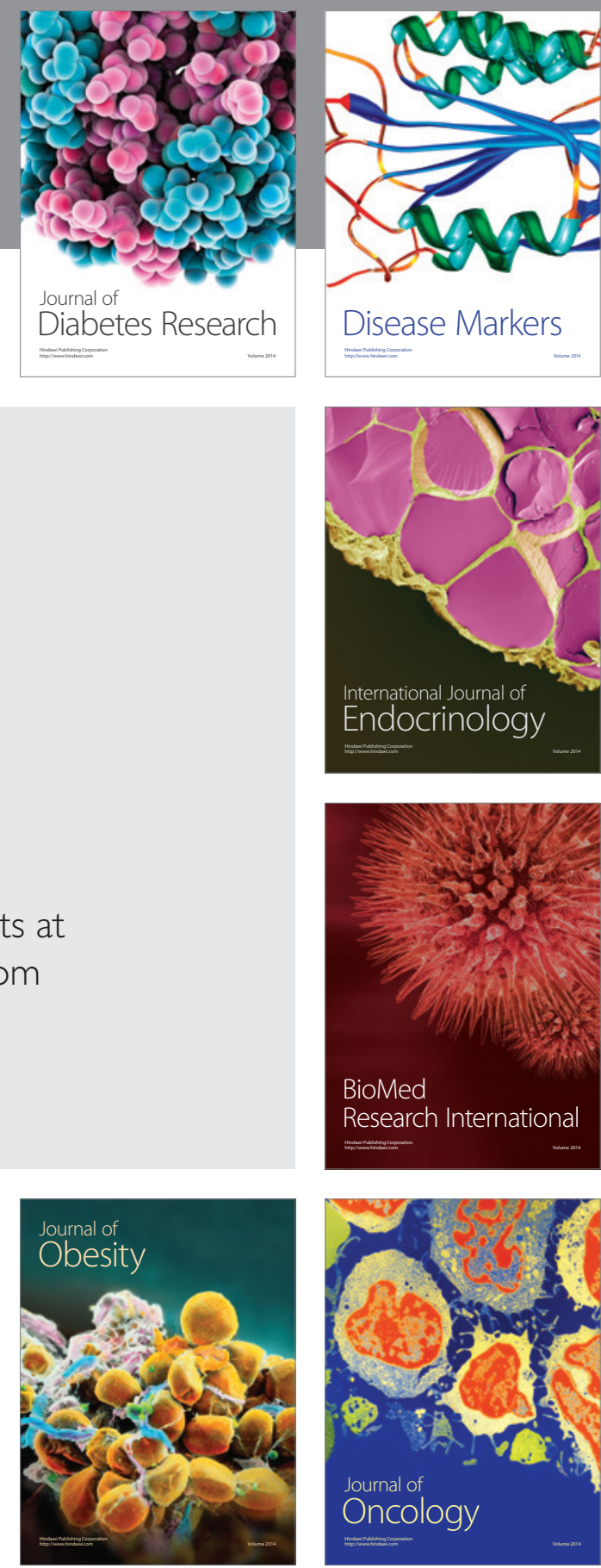

Disease Markers
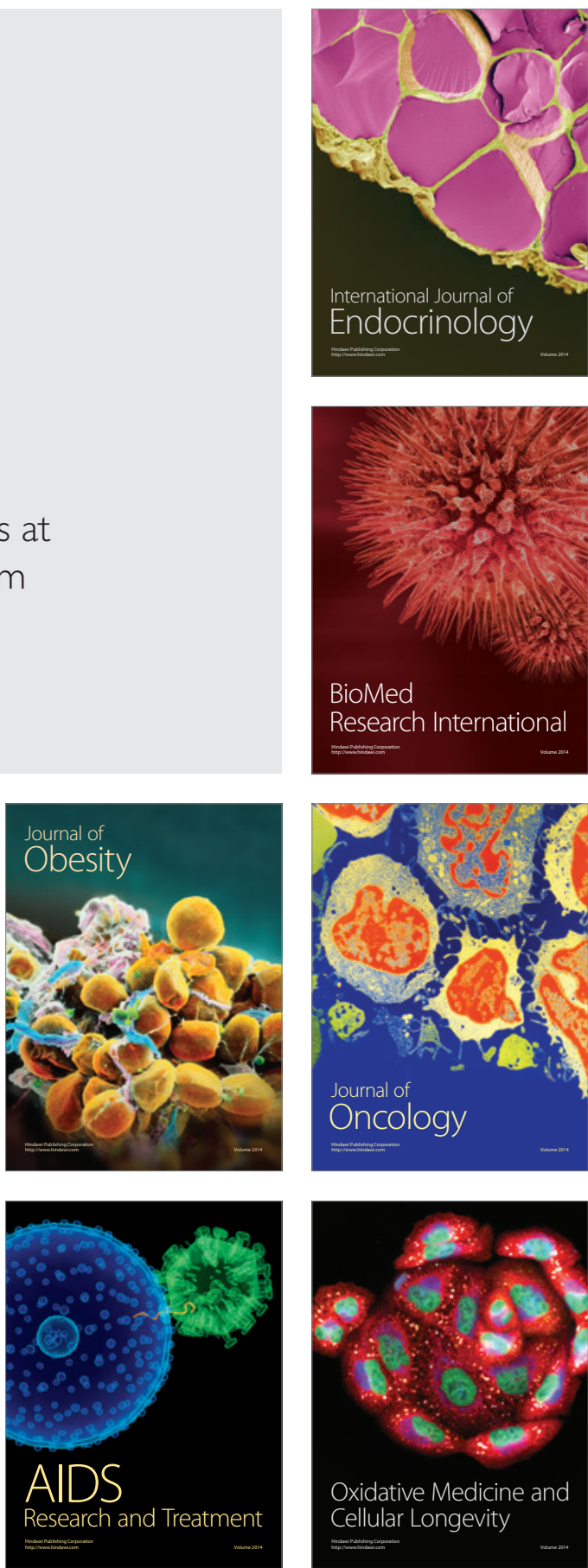